\title{
Review
}

\section{Freedom beyond sovereignty: Reconstructing liberal individualism}

\author{
Sharon R. Krause, \\ University of Chicago Press, Chicago, 2015, 272pp., ISBN: 9780226234694
}

Contemporary Political Theory (2017) 16, 398-401. doi:10.1057/s41296-016-0078-7; advance online publication 16 November 2016

What is freedom? Prompted by deep concern about the lack of freedom that many people experience in today's "ostensibly free societies" (p. 19), particularly America, Sharon Krause goes to the heart of this question in Freedom Beyond Sovereignty. We do not fully know what freedom means, even if many of us think they do, and this fact obstructs our ability to diagnose and contest pervasive failures of freedom - preventing us, for example, from understanding how inequalities associated with race, gender, and sexual orientation constitute a problem of freedom, not just social justice. To address this, Krause offers her own distinctive account of what freedom is, and in the process of doing so, she aims to "reconstruct" liberalism in order to make it more responsive to experiences of oppression.

To begin more or less where Krause finishes, freedom is not one thing but several. In chapter 4, she discusses four contemporary theories of political freedom: non-interference (as defended by Berlin), non-domination (Pettit), non-oppression (articulated by Krause herself), and collective world-making (Arendt). Each captures a genuine aspect of freedom, but none of them captures the phenomenon in all of its various manifestations. Moreover, by declaring one particular form of freedom to be the essence of freedom, these theories manifest massive blind spots for some of the most pernicious failures of freedom experienced today. These theories and their limitations are for the most part familiar. But Krause's treatment of them is lucid and enriched by her admirable ability, on display throughout the book, to provide apt examples that both illuminate a theoretical point and articulate experiences of un-freedom. These examples are drawn from a broad range of literary and theoretical sources as well as personal experiences, and there is much to be learned from them.

Krause intends to hang on to what is important in each of these "monistic" views of political freedom by integrating them, with a little tweaking, into a "pluralist" conception of freedom (chapter 5). She argues that we do not need, and indeed ought not, to choose among them - at least, not at a theoretical level. In

(c) 2016 Macmillan Publishers Ltd. 1470-8914 Contemporary Political Theory Vol. 16, 3, 398-401 www.palgrave.com/journals 
practice, different forms of freedom often conflict, and there are trade-offs and tragic choices to be made. Still, to adequately understand such choices, Krause insists that we must at the least recognize that there are genuine but conflicting claims of freedom at stake.

The result is a much broader and more complex notion of freedom than the familiar alternatives. But it is no incoherent jumble, because Krause argues that there is still a basic unity to the concept. At bottom, freedom refers to the "enabling conditions" that make agency possible. Because these enabling conditions are pluriform, freedom takes various forms as well. The association of freedom with agency would hardly be remarkable, were it not that Krause seeks to fundamentally challenge common conceptions of what agency consists in - assumptions that she believes prevent us from grasping the full range of forms of freedom.

That brings us to the philosophical heart of the book: an innovative, "nonsovereign" theory of agency (chapter 1). The sovereignty beyond which freedom lies, as the title suggests, is that of the individual, not the state. Krause believes that prominent views of agency embody an aspiration to sovereignty, in that the individual agent's intentions are taken to be decisive. "We hold to a sovereigntist view of agency to the extent that we identify agency in the ideal case with being in control of one's action, where the content of one's will defines the meaning of the action, and one's effects manifest one's own reasoned choices rather than the wishes of others or the random effects of chance" (p. 3). According to Krause, this overstates the role of intention in agency. For her, agency is "the affirmation of one's subjective existence, or personal identity, through concrete action in the world. To be an agent is to have an impact on the world one can recognize as one's own" (p. 4). On this alternative view, agency is non-sovereign because "the exercise of agency regularly comes apart from intentional choice and consistently eludes individual control" (p. 21). There is much to be said about Krause's proposal, but I can only provide a bare outline here.

Krause argues that agency is radically non-sovereign for two basic reasons. Socially speaking, successful action depends on others to carry it through. One cannot fully predict or control the consequences of one's actions. This means, for Krause, that action is deeply intersubjective: it is a "socially distributed phenomenon" (p. 4). How others understand and respond to us determines the quality of our agency, as in this example of frustrated agency:

[W]hat [the youngish black man] Daryll is "doing" in piloting his expensive car around town, given the broader background of racialized social expectations, includes raising a red flag of potential criminality. Against this broader background, his action has meaning and effects that go beyond anything contained in his own understanding of it ... If what really happens to him when he drives his Lexus is that he is criminalized and humiliated by others, then although he may have managed to pilot his vehicle across town 
he has not after all succeeded in affirming his subjective existence concretely in the world (p. 63).

Second, agency is also "materially distributed" (p. 21): it is manifested by our bodies in ways that cannot be fully traced back to our intentions. Many things we do unintentionally or while intending something else are nonetheless expressions of our agency, in Krause's view:

By blushing involuntarily in your presence I may disclose that I am intimidated by you, for example, and I may regret this disclosure. Because we so thoroughly identify agency with intentional choice, bodily reactions like these are typically treated as being orthogonal to agency. Yet what we commonly say in describing them tells a different story. We say, "I blushed," or "I grimaced," thus acknowledging the relationship between our bodies, our identities, and our deeds, a relationship that sometimes contravenes our intentions. If a bodily act has an impact on the world that manifests key features of the agent's identity, then it makes sense to see it as part of her agency (p. 43).

Crucially, these arguments are not meant to debunk agency, but to call the link between actions and intentions into question. In Krause's view, we can be free and responsible agents, even if our actions are beyond our intention or control. And recognizing the ways in which we are non-sovereign is crucial to identifying the conditions for our agency and for diagnosing the ways in which these are thwarted. Krause is not the first to propose a non-sovereign conception of agency. Both Arendtians (discussed at length in the book) and Hegelians (curiously absent) will find parts of this story familiar (see McFadden, 2015). Still, Krause's account is particularly compelling and elegantly presented, with many tangible examples and little jargon.

Krause proceeds to analyze the enabling conditions for agency, arguing that some of the main contemporary obstacles to freedom have to do with social inequality and informal and implicit forms of oppression, marginalization, and stigmatization (chapter 2). "Because agency is not simply an internal property of the person but a socially distributed phenomenon, inequality attacks agency at its core, ... unsettling its very foundations" (p. 58). This is an important point, and it provides good reasons for thinking that inequality ought to be a central concern for liberals, as Krause wants to show. Still, I am not sure how revolutionary that thought is in the context of liberal political theory, and because Krause does not engage with recent work in that area, some of which seems to have moved in similar directions (e.g., theories of recognition and social conceptions of autonomy), she leaves the promise of her subtitle, to "reconstruct liberal individualism," less than fully fulfilled.

Given the extent of her theoretical ambitions - to profoundly rethink political freedom and reorient liberalism - Krause also has surprisingly little to say about 
political institutions and the state. Nor about democracy, for that matter: the notion of freedom as self-legislation does not figure in the book. While Krause radically challenges the sovereignty of the individual, she does not question the sovereignty of the state. It seems as though, for Krause, the state is basically benign, not a problem for freedom - an impression that libertarians, radical democrats, and frankly anyone who observes the state of electoral and plebiscitary politics today should find troubling. Admittedly, Krause's intent is to focus "less on formal political institutions and laws than on informal, interpersonal dynamics, cultural values, and social practices" (p. 11). And this focus enables her to bring informal and implicit dangers to freedom into sharp relief. Still, these are not mutually exclusive concerns, and without further reflection on the implications of nonsovereign freedom for thinking about the state, law, and democracy, the project feels somewhat unfinished.

Even so, Freedom Beyond Sovereignty is an important work of political theory that admirably combines theoretical innovations with critical diagnoses of contemporary ills. Highly recommended for anyone thinking about freedom, equality, agency, or liberalism.

\section{Reference}

McFadden, T.J. (2015) The Weight of Freedom: Political Integrity and Non-sovereign Autonomy. PhD Dissertation, University of Chicago.

Thomas Fossen Institute for Philosophy, Leiden University, P.O. Box 9515, 2300 RA Leiden, The Netherlands t.fossen@phil.leidenuniv.nl 